Priestley, M. and Sinnema, C. (2014). Downgraded curriculum? An analysis of knowledge in new curricula in Scotland and New Zealand. Curriculum Journal, Special Edition: Creating Curricula: Aims, Knowledge, and Control

\title{
Downgraded curriculum? An analysis of knowledge in new curricula in Scotland and
}

New Zealand

\author{
Mark Priestley $^{\mathrm{a}}$ and Claire Sinnema ${ }^{\mathrm{b}}$ \\ a. University of Stirling \\ b. The University of Auckland
}

Correspondence details: Professor Mark Priestley, School of Education, University of Stirling, Stirling FK11 7BW. Email m.r.priestley@stir.ac.uk

\begin{abstract}
The development, since 2000, of new National Curricula across the Anglophone world signals a number of policy trends, including: a move from the explicit specification of content towards a more generic, skills-based approach; a greater emphasis on the centrality of the learner; and [ostensibly] greater autonomy for teachers in developing the curriculum in school. These policy shifts have attracted some criticism, especially from social realist writers, who claim that the new curricula downgrade knowledge. This paper offers a contribution to this debate; an empiricallybased analysis of two new curricula, New Zealand's Curriculum Framework and Scotland's Curriculum for Excellence. We conclude that, while these curricula continue to accord considerable importance to knowledge in their statements of policy intent, the social realist critique is at least partially justified, since both curricula are characterised by a lack of coherence and mixed messages about the place of knowledge.
\end{abstract}

Keywords: curriculum; curriculum policy; knowledge; social realism 


\begin{abstract}
'New Zealand's school curriculum has been hollowed out of knowledge as academic learning is increasingly abandoned for a misguided focus on skills and the process of learning' (New Zealand Herald, 2013)
\end{abstract}

\title{
Introduction
}

Since the turn of the millennium, Anglophone education systems have witnessed a curricular turn (for an overview of trends and commonalities, see Sinnema \& Aitken, 2013. See also: Wheelahan, 2010; Young, 2009). This 'new curriculum' (Biesta \& Priestley, 2013) is associated with moves prompted by globalisation to position education systems more widely, and curriculum in particular, as drivers of economic development and national competitiveness (Yates \& Young, 2010). While the 'new curriculum' varies in form from country to country, researchers have identified a number of common features. It is claimed that these include: a shift from the prescriptive specification of knowledge content evident in many earlier national curricula to what Young (2008a) has termed genericism ${ }^{1}$; a new focus on the centrality of the learner, accompanied by the development of active forms of pedagogy and a view of teachers as facilitators of learning (Sinnema \& Aitken, 2013); the articulation of curriculum as assessable outcomes, modular courses and ladders of qualifications (Young 2008), accompanied by increasingly pervasive regimes of accountability and cultures of performativity (Priestley, Robinson \& Biesta, 2012).

The new curriculum has attracted its share of controversy and criticism, as illustrated by the quotation at the head of this paper, taken from a New Zealand daily newspaper ${ }^{2}$. It is this

\footnotetext{
${ }^{1}$ We note here that in at least two Anglophone countries, this trend has stuttered or even reversed; in England, following the election of a Conservative government in 2010, there has been a return to the specification of 'essential' content, inspired by E.D. Hirsch's notion of cultural literacy (see, for example, http://www.theguardian.com/education/2012/oct/15/hirsch-core-knowledge-curriculum-review); in Australia, the nascent National Curriculum looks set to follow similar trends (Brennan \& Zipin, 2013). This serves to remind us that curriculum policy making is an inherently political business, subject to the vagaries of local politics and concerns, as well as to global pressures and trends.

${ }^{2}$ The article in question was reporting the award of the prize for the best paper of the year (2013) by the British Educational Research Journal to a New Zealand Academic, Elizabeth Rata, for her article 'The politics of knowledge in education (see Rata, 2012a). Rata has been extremely critical of the curricular directions taken in New Zealand and elsewhere.
} 
Priestley, M. and Sinnema, C. (2014). Downgraded curriculum? An analysis of knowledge in new curricula in Scotland and

New Zealand. Curriculum Journal, Special Edition: Creating Curricula: Aims, Knowledge, and Control

critique of a claimed 'downgrading' of knowledge (Yates \& Collins, 2010) in the 'new curriculum' that provides the focus for this paper. We first provide a brief overview and analysis of the critique provided by social realists such as Michael Young. Social realism has offered a powerful critique of modern trends in curriculum development - arguably the most significant challenge to what they refer to as technical-instrumentalist curricula (Moore \& Young, 2001) - and is thus fundamental to any treatment of the issue of knowledge and the 'new curriculum', whether one agrees or not with their arguments. In this paper, we offer an empirical contribution to these recent debates about curriculum and knowledge, examining the extent to which the above claims about the downgrading of knowledge are justified. In doing so, we draw upon two case studies, Scotland's Curriculum for Excellence and the New Zealand Curriculum, both of which exhibit many of the common features outlined above.

\section{Knowledge and the 'new curriculum'}

Social realist writers (for example, Rata, 2012b; Wheelahan, 2011; Young, 2007) have highlighted a worldwide trend for new curricular models to downgrade knowledge. Their critique is reflected to some extent in anxieties expressed more widely about the curricular turn towards technical-instrumentalism (for example, Biesta, 2011; Ecclestone, 2013; Priestley, 2011; Watson, 2010; Yates \& Collins, 2010).

This curricular turn has at least two dimensions. First, critics point to an overt shift from the specification of disciplinary knowledge to an emphasis on the development of generic skills, often with an instrumental focus on citizenship and/or the workplace. Within our two case studies, the specification of key capacities or competencies to be achieved by education might be seen as evidence of this shift: Scotland's Curriculum for Excellence aims to develop students as Successful Learners, Confident Individuals, Effective Contributors and Responsible Citizens (Scottish Executive, 2004a); in similar fashion, the New Zealand 
Priestley, M. and Sinnema, C. (2014). Downgraded curriculum? An analysis of knowledge in new curricula in Scotland and

New Zealand. Curriculum Journal, Special Edition: Creating Curricula: Aims, Knowledge, and Control

Curriculum specifies five key competencies - thinking, using language, symbols, and texts, managing self, relating to others, participating and contributing (New Zealand Ministry of Education, 2007). This new focus on 'setting out not what children are expected to know, but how they should be' (Watson, 2010, p. 99) is seen by some to be sinister, with overtones of indoctrination and totalitarianism. It has also been alleged by critics to over-simplify and dichotomise the complex relationship between knowledge and skills, obscuring the relationship between different forms of knowledge. For example, Young (2009, p.4) has questioned whether such generic skills can indeed be developed free of contextual knowledge and 'free of the domains in which they are realised'.

The turn towards competencies and capabilities in many of the most recent revisions to national curricula gives rise to the question of temporality in the emergence and circulation the 'new curriculum'. That question deserves detailed attention that is beyond the scope of this paper. It is clear, though, that there is 'cross-national attraction associated with policy borrowing, described by Phillips \& Ochs (2003) across global curriculum policy, for example in the case of lifelong learning. That concept has become, due to policy diffusion, widely adopted in education policy, according to Jakobi (2012). The wide adoption, she suggests, is due to the success of international organisations in disseminating educational policy ideas which lead to common goals across nations. A second example lies in the specification of competencies and capabilities in national curricula; the Organisation for Economic Development 'DeSeCo' project (Definition and Selection of Competencies) is widely cited as influencing the inclusion of such competencies in curriculum.

A second key feature of the social realist critique lies in the distinction between everyday and disciplinary knowledge, and the increasing emphasis on inter-disciplinary approaches to organising the curriculum has thus attracted their criticism. For instance, 
Priestley, M. and Sinnema, C. (2014). Downgraded curriculum? An analysis of knowledge in new curricula in Scotland and

New Zealand. Curriculum Journal, Special Edition: Creating Curricula: Aims, Knowledge, and Control

Young and Muller (2010) have claimed that a weakening of traditional subject boundaries is problematic. They see an erosion of the distinction between academic knowledge and everyday knowledge, a weakening of the relations between the knowledge in academic disciplines and what is taught in schools, and an attendant danger that, in the lack of specification of content, less experienced teachers will 'fall behind without knowing it, or miss out conceptual steps that may be vital later on' (p. 23). They claim that denying young people access to the 'powerful knowledge' enshrined in disciplines is detrimental to their life chances, a theme echoed by Rata (2012a, b), who warns of the social exclusion inherent in the 'new curriculum'. Such views are rooted in an 'assumption [..] that the acquisition of knowledge is the key purpose that distinguishes education, whether general, further, vocational or higher, from all other activities' (Young, 2007, p. 81, emph. in original).

As stated above, the issue of knowledge in the curriculum has been a cause for concern amongst educationalists beyond social realism. However, whether Wheelahan's (2010) 'crisis of curriculum' is a reality is more open to debate. There are a number of caveats to offer here. First, one might question whether the distinction between everyday knowledge and disciplinary knowledge is as clear cut as might be suggested by some of the social realist literature or indeed whether skills and knowledge are as neatly separable as suggested. For example, Gill and Thomson (2012) suggest that this is a false dichotomy, and that high level knowledge is really the skill of being able to differentiate between concepts. Linked to these questions, is the issue of whether it is appropriate for the school curriculum to focus entirely on disciplinary knowledge; it is fair to say that the powerful arguments of the social realists are countered by equally powerful discourses that suggest that it is the business of schools to shape the individual, develop attributes and dispositions and teach everyday knowledge that has practical utility for everyday life (for example, see: Gardner, 1991; Kelly, 1999; White, 
Priestley, M. and Sinnema, C. (2014). Downgraded curriculum? An analysis of knowledge in new curricula in Scotland and

New Zealand. Curriculum Journal, Special Edition: Creating Curricula: Aims, Knowledge, and Control

2011). Such authors have offered progressive views of curriculum, whereby content is selected to address educational purposes, for example the development of the potential for active citizenship, rather than being included in the curriculum because it reflects disciplinary knowledge. This is not to suggest that such approaches negate the place of knowledge in curriculum or even the selection and organisation of content through traditionally recognised subjects. For example, Dewey (1907) explicitly rejected what he saw as the false dichotomy of knowledge and process, emphasising the importance of the 'accumulated wisdom of the world'.

Second, even if we accept the premise that school knowledge should be drawn from disciplines, this is not the same as saying that it should be framed around traditional subjects as is sometimes advocated by social realists. As Whitty (2010, p. 34) points out, 'knowledge is not the same as school subjects and school subjects are not the same thing as academic disciplines'. It is perfectly possible to conceive alternative rigorous approaches to teaching disciplinary knowledge that are inter-disciplinary in nature, rather than being framed as traditional subjects (for example, see Beane, 1997). The social realist literature tends to advocate traditionalist approaches to defining school subjects, but is less clear in delineating subjects from disciplines than it is in illustrating how knowledge is socially formed into disciplines. In the latter case, a convincing case is made for the intellectual legitimation of knowledge over time within the institutional structures of academic disciplines. Here, drawing upon the work of Basil Bernstein (e.g. 1990), both the social origins and academic legitimacy of disciplinary knowledge are clearly demonstrated. However, the case is less clearly made for justifying school subjects, social constructs like disciplines, but arguably lacking their high level of intellectual legitimacy (see Goodson \& Marsh, 1996) 
Priestley, M. and Sinnema, C. (2014). Downgraded curriculum? An analysis of knowledge in new curricula in Scotland and

New Zealand. Curriculum Journal, Special Edition: Creating Curricula: Aims, Knowledge, and Control

A third issue for debate is hinted at in Young's (2007) distinction between routinised and reflexive engagement with knowledge. Young, drawing upon Davydov, points out that 'much of schooling [consists] of the routinized [sic] acquisition of scientific concepts' (p. 53). Thus it is not clear, even where school knowledge is disciplinary in origin in line with social realist arguments, that it necessarily constitutes the sort of powerful knowledge advocated by Young. It is worth noting here that 'new curricula' around the globe tend to advocate active and constructivist forms of pedagogy that are said to encourage the development of deep understanding of concepts (presumably reflexive acquisition of knowledge), but that many social realists reject these approaches as synonymous with relativist, constructionist notions of knowledge (for example, Rata, 2012b).

While we briefly note the above issues as interesting facets of the debate on knowledge in the curriculum, they are nevertheless peripheral to this paper. Our interest here has a more practical focus, concerning the degree to which social realist claims about the downgrading of knowledge in the 'new curriculum' are empirically sustainable. For the purposes of this paper we examine two examples of the 'new curriculum, Scotland's Curriculum for Excellence (CfE) and the New Zealand Curriculum. There are two levels of analysis undertaken in the paper:

- At the high level of curriculum statements, or in terms of policy intention. The key question here is whether these curricula sufficiently emphasise the importance of knowledge, or whether the social realists are justified in making the claims that they downgrade knowledge

- At the operational level of the working documents. Our concern here is to identify whether the working documents of the curricula provide adequate 
Priestley, M. and Sinnema, C. (2014). Downgraded curriculum? An analysis of knowledge in new curricula in Scotland and New Zealand. Curriculum Journal, Special Edition: Creating Curricula: Aims, Knowledge, and Control

guidance for practitioners as they develop the curriculum in situ. There are two main approaches to facilitate the specification of content at this level: the first is the specification of 'important content', that is input regulation of the curriculum (Nieveen \& Kuiper, 2012); the second relates to the existence or otherwise of clear processes for content specification, to guide practitioners as they engage in school-based curriculum development.

\section{The case study contexts}

Before undertaking our analysis, we first provide a brief overview of the background and key features of each curriculum. Space precludes a detailed description or analysis.

\section{The Curriculum for Excellence Case}

Curriculum for Excellence (CfE) was launched in 2004, when the Scottish Executive published a paper titled A Curriculum for Excellence: The Curriculum Review Group (Scottish Executive, 2004a). The central feature of CfE is the specification of four key capacities, along with accompanying descriptor statements, which are to be promoted through a child's education: successful learners; confident individuals; responsible citizens; effective contributors (p. 12).

The 2004 discussion paper did not offer an extended justification for its terminology or structure, and should be regarded as a macro-level framework, designed to form the basis of subsequent policy development. It was accompanied by the Ministerial Response (Education Scotland, 2004b), which set out future directions for the new curriculum in a more concrete manner than did the review document, laying out, for example that the new curriculum would be articulated as 'clear statements of the outcomes which each young person should aspire to achieve' (p. 4) and hinting that subjects would continue to be the basis of the curriculum. In 2006, the publication of A Curriculum for Excellence: progress and proposals (Education 
Priestley, M. and Sinnema, C. (2014). Downgraded curriculum? An analysis of knowledge in new curricula in Scotland and

New Zealand. Curriculum Journal, Special Edition: Creating Curricula: Aims, Knowledge, and Control

Scotland, 2006) added more detail, emphasising the importance of engagement by teachers, the centrality of learning and teaching and the unification of the curriculum from 3-18. This document outlined a series of six sequential levels, establishing the principle that 'expectations will be described in terms of experiences as well as broad significant outcomes' and that these would be 'designed to reflect the Four Capacities' (p. 12). Significantly, it was proposed at this stage that the curriculum would be structured around domains of knowledge, as was the case for previous Scottish curricula ${ }^{3}$.

Further guidance has emerged since 2006. This includes the Building the Curriculum series, which for example has provided additional guidance on the eight curricular categories outlined above, the early years curriculum and assessment, and experiences and outcomes (Es \& Os) in each of eight curricular areas (Education Scotland, 2013). These follow a formulaic structure, seeking to combine within simple statements, set out in hierarchical levels, both the expected outcomes of learning and the experiences through which the outcomes might be achieved. The following examples from Science give a flavour of these:

By contributing to experiments and investigations, I can develop my understanding of models of matter and can apply this to changes of state and the energy involved as they occur in nature. [SCN 2-05a]

Through research on how animals communicate, I can explain how sound vibrations are carried by waves through air, water and other media. [SCN 2-11a]

(Education Scotland, 2013)

\section{The New Zealand Curriculum Case}

The New Zealand Curriculum (NZC) was launched in 2007 following a curriculum stocktake (Le Métais, 2002; Australian Council of Education Research, 2002) and a lengthy

\footnotetext{
${ }^{3}$ Health and Wellbeing, Languages, Mathematics, Science, Social Studies, Expressive Arts, Technologies, and Religious and Moral Education
} 
Priestley, M. and Sinnema, C. (2014). Downgraded curriculum? An analysis of knowledge in new curricula in Scotland and

New Zealand. Curriculum Journal, Special Edition: Creating Curricula: Aims, Knowledge, and Control

and inclusive curriculum development process between 2004 and 2007. That process involved more than 15,000 students, teachers, principals, advisers, and academics in the development, trialing and response to a draft curriculum in 2006 and the subsequent revisions in the 2007 final version.

Key shifts in the NZC (2007) from previous curricula, were the inclusion of all learning areas in a single policy document, the specification of key competencies (rather than essential skills) - thinking, using language, symbols, and texts, managing self, relating to others, participating and contributing, a section on effective pedagogy, and the repositioning of specific achievement objectives as guidelines (leaving single page learning area statements as the compulsory aspect). The NZC is also characterised by an emphasis on school-level curriculum autonomy and flexibility - the document is intentionally broad, with a section on school-based curriculum design and review that places the onus for development of schoollevel curriculum firmly on practitioners. In this way, the policy achieves the goal set out in the development process of reducing, refining and clarifying the curriculum - curriculum intentions are set out in broad terms and it signals that responsibility for specifics rests with schools.

Like CFE, the NZC continued the tradition of using domains of knowledge as a curriculum organiser - while guidance suggested those domains not be required as the structure for delivery of the curriculum, learning areas persisted as a means of organising achievement objectives. The following examples from Science, Social Studies and Mathematics illustrate their format:

\footnotetext{
Students will recognise that there are life processes common to all living things and that these occur in different ways. (Science, Level 3, Living World)

Students will gain knowledge, skills and experience to: Understand how groups make and implement rules and laws. (Social Sciences, Level 3)
} 
Priestley, M. and Sinnema, C. (2014). Downgraded curriculum? An analysis of knowledge in new curricula in Scotland and

New Zealand. Curriculum Journal, Special Edition: Creating Curricula: Aims, Knowledge, and Control

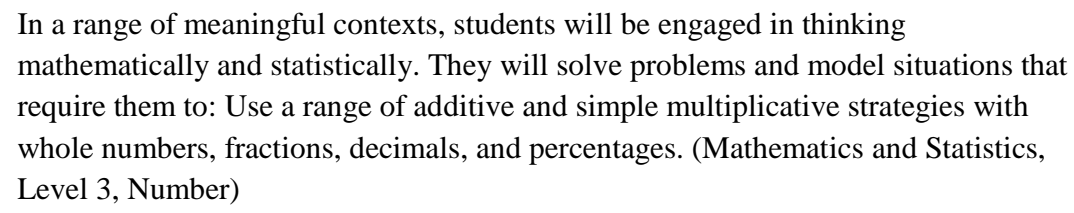

A national evaluation of the implementation of the NZC (Sinnema, 2011) revealed that educators in both primary and secondary schools held the curriculum in high regard. They typically viewed it positively, considered it to be an improvement on the previous curriculum, and were committed to implementing it. That commitment was somewhat challenged by policies released soon after the NZC, outlining national standards for reading, writing and mathematics. While described by the Ministry of Education as standards to support the curriculum itself, many educators believed that the stipulation of national standards and the subsequent necessity to focus on traditional curriculum outcomes compromised the freedom and autonomy needed to give effect to a curriculum that was broad, forward-looking and responded to local needs and desires.

\section{Methodology}

In conducting our analysis, we used a case study approach, employing document analysis to examine curriculum policy texts from the two contexts. The purpose of looking to policies from both countries was not specifically to compare the contexts of these two curricula, but rather to enable broader consideration of the ways in which they position knowledge. The document analysis approach (Rapley \& Jenkings, 2010) dealt with actual textual content - we examined the frequency, nature and type of mentions of knowledge using quantitative content analysis (Weber, 1990). It also dealt with extra-textual content of the documents, as we analysed the contextual and design features of the curriculum policy texts (organisation and structure) that provide messages about the status of knowledge, using qualitative content analysis (Pickering, 2004). 
Priestley, M. and Sinnema, C. (2014). Downgraded curriculum? An analysis of knowledge in new curricula in Scotland and

New Zealand. Curriculum Journal, Special Edition: Creating Curricula: Aims, Knowledge, and Control

\section{Research questions}

Within the two levels of analysis specified above, we posed the following questions relating to the overarching question about whether these curricula downgrade knowledge:

1. How is knowledge positioned in national curricula statements of intent?

2. How is knowledge positioned in operational guidance aspects of national curricula?

3. How consistent are the messages about the positioning of knowledge in curricular policy?

4. Do these curricula downgrade knowledge?

\section{Sampling and Analysis}

There are multiple documents that outline $\mathrm{CfE}^{4}$, in contrast with just one Englishmedium document in New Zealand ${ }^{5}$. Therefore, when analysing the two sets of documents, we needed to give careful consideration to identifying sections of text that are directly comparable in their attention function as providing statements of intent (both overall and for curriculum/learning areas) and operational guidance. The selection of these documents and sections of them was also based on their status as key policy documents, recognized as such by practitioners. Furthermore they were considered likely sites of signals about the position of knowledge in the curriculum, since they set out both curriculum intentions and operational guidance.

\footnotetext{
${ }^{4}$ Note that unless stated otherwise, all CfE documents are assumed to be sourced from the Curriculum for Excellence webpage at Education Scotland (Education Scotland, 2013)

${ }^{5}$ In New Zealand there are two partner curriculum documents. The New Zealand Curriculum in English and Te Marautanga in Maori for Maori-medium schools. All references in this paper are drawn from the Englishmedium version (New Zealand Ministry of Education, 2007).
} 
Priestley, M. and Sinnema, C. (2014). Downgraded curriculum? An analysis of knowledge in new curricula in Scotland and

New Zealand. Curriculum Journal, Special Edition: Creating Curricula: Aims, Knowledge, and Control

Statements of intent included in the analysis from the NZC were drawn from the section typically referred to in New Zealand as 'the front end', which outlines overall curriculum purpose (pages 1-15) and the series of pages in the middle of the document that outline statements of purpose for each of the eight learning areas (pages 16-33). Equivalent material from CFE was drawn from 'Building the Curriculum 3: A framework for learning and teaching' and also the statements about 'Principles and Practice' relating to each curriculum area in the 'CFE Experiences and Outcomes' document.

The CFE 3 sections indicated above were selected since they were comparable to the NZC statements of intent. They outlined overall curriculum purpose and structure in relation to the Scottish curriculum and, while duplicating ideas presented in the 2004 review document, these sections provided an overall framework most similar in scope and level of detail to that of the NZC. The sections introducing each curriculum area in the 'CFE Experiences and Outcomes document' (preceding the pages with tables of outcomes) were similar in nature to the 'one-pagers' about each learning area in the NZC.

Operational guidance included in the analysis from the NZC was situated in the achievement objectives set out for each of the learning areas for the eight achievement levels of the curriculum. The CFE equivalent material is found in the introductory statements and statements of experiences and outcomes in the 'CFE Experiences and Outcomes' document.

These sections of operational guidance from the two curricula were selected since they were similar in scope and detail. The leveled statements of specific desired outcomes in the NZC are organized around learning areas, just as the CFE statements of specific experiences and outcomes are organized around curriculum areas at particular levels. 
Priestley, M. and Sinnema, C. (2014). Downgraded curriculum? An analysis of knowledge in new curricula in Scotland and

New Zealand. Curriculum Journal, Special Edition: Creating Curricula: Aims, Knowledge, and Control

To address the first research question, we subjected the main macro-level documents to a keyword search for mentions of the terms 'knowledge', 'knowledges', and 'know'. Entire sentences in which those terms were used were added to a database for analysis. Mentions relating specifically to 'prior knowledge' were excluded, since these typically referred to desired pedagogical approaches (linking to prior knowledge) rather than to desired outcomes. A deductive coding framework was developed to examine how knowledge is positioned in each curriculum, for example the extent to which knowledge is treated as an end (having intrinsic value), or as a means (having instrumental value), and the extent to which it is treated as an exclusive aim or not. The framework is outlined in Appendix A.

Data were analysed using SPSS. This allowed calculation of frequency counts of total references to knowledge in each of the curricula along with references categorised, for example, as having intrinsic or instrumental value. Using cross tabs we were able to compare whether the references outlined above were in statements of intent or in statements of operational guidance. To establish inter-rater reliability in the coding outlined above, a random sample of just over $10 \%$ of the total knowledge statements $(n=60)$ were coded by a second coder, who disagreed with the original coder on only 2 of the 120 coding decisions for those statements, indicating inter-rater reliability in excess of $98 \%$.

To address the second research question, we looked specifically at the messages relating to knowledge that aimed more explicitly at framing practice. Analysis of these documents focused on two main aspects: 1) the positioning of references to knowledge in relation to disciplines, domains of knowledge and/or subjects; and 2) the positioning of references to knowledge relative to other curricular elements, such as skills, competencies and capabilities.

Throughout the analysis of both macro-level intentions and specific curricular guidance, we were concerned to track the consistency of messages about knowledge as well as their 
Priestley, M. and Sinnema, C. (2014). Downgraded curriculum? An analysis of knowledge in new curricula in Scotland and

New Zealand. Curriculum Journal, Special Edition: Creating Curricula: Aims, Knowledge, and Control

overall clarity and specificity, and to ultimately address the question of whether these curricula downgrade knowledge.

\section{Findings}

\section{Curricular emphases on knowledge in policy intentions and operational guidance}

We first examined how these curricula make general references to knowledge. As expected, there were multiple references to knowledge in both the NZC $(n=128)$ and the CFE $(n=270)$ documents analysed. While it did not make sense to directly compare the above frequency counts, since the size of the documents varied, it is valid to compare the proportions of such references since this indicates the priority given within the curricula to knowledge. It is therefore significant that more than $17 \%$ of the mentions of knowledge in the NZC sources were in sections outlining curricular intent. This compares with less than 5\% within CfE. In both policies, the premise that knowledge matters is apparent through the positioning of statement promoting knowledge in prominent high level sections of the documents. For example, the CfE policy framework states clearly that:

\footnotetext{
All children and young people in Scotland have an entitlement to a curriculum which will support them in developing their values and beliefs and enable them to: develop knowledge and understanding of society, the world and Scotland's place in it (CfE, Building the Curriculum 3, p. 14)
}

Similarly, in the NZC foreword (New Zealand Ministry of Education, 2007), knowledge is the first in a list of purposes: 'a framework designed to ensure that all young New Zealanders are equipped with the knowledge, competencies, and values they will need to be successful citizens in the twenty-first century' (p. 4). It also features in statements about the vision set out for young people, who "will continue to develop the values, knowledge, and competencies that will enable them to live full and satisfying lives"; (p. 8). Such statements indicate strongly that the policy intent in both curricula is to emphasise the importance of knowledge in developing the person. 
Priestley, M. and Sinnema, C. (2014). Downgraded curriculum? An analysis of knowledge in new curricula in Scotland and

New Zealand. Curriculum Journal, Special Edition: Creating Curricula: Aims, Knowledge, and Control

However, in CFE, a greater proportion $(31 \%)$ of the knowledge references were positioned in the sections about particular curriculum areas than was the case in the NZC (23\%). The tendency in the Scottish context for knowledge mentions to be prevalent in curriculum area intention statements perhaps signals a stronger connection between knowledge and the curriculum areas with their disciplinary underpinnings. (However, as we noted previously, the subject domains in CfE were inherited from previous curricula, so this in no way implies that there has been a systematic attempt to redefine curricular content, only that there is perhaps a taken-for-granted assumption that knowledge is important.)

In both contexts, more than $60 \%$ of the mentions of knowledge were in the section that outlined specific outcomes (as opposed to more general documentation that related to subject areas): achievement objectives as outlined for each learning area in the case of the NZC, and experiences and outcomes for each curriculum area in the case of CFE.

\footnotetext{
Within the modern languages framework young people will demonstrate their progression as they move through levels in terms of increasing awareness of language rules, including knowledge about language (CFE, Experiences and Outcomes, p. 175)

As they engage with and develop knowledge and deeper understandings of music, they draw on cultural practices and on histories, theories, structures, technologies and personal experiences (NZC, The Arts, p. 21)
}

We will come back in due course to the question of whether these latter references in the outcomes documents are closely linked to disciplinary knowledge, or whether they simply refer to knowledge in a generic way. Table 1, below, provides detail about the proportions of such references to knowledge in different sections of the curriculum documentation. 
Priestley, M. and Sinnema, C. (2014). Downgraded curriculum? An analysis of knowledge in new curricula in Scotland and

New Zealand. Curriculum Journal, Special Edition: Creating Curricula: Aims, Knowledge, and Control

Table 1: References to knowledge in the New Zealand and Scottish curricula

\begin{tabular}{lccr}
\hline & $\begin{array}{c}\text { The New Zealand } \\
\text { Curriculum (NZC) }\end{array}$ & $\begin{array}{c}\text { Curriculum for } \\
\text { Excellence } \\
\text { (CFE) }\end{array}$ & $\begin{array}{c}\text { Combined NZC } \\
\text { and CFE }\end{array}$ \\
\hline Intent: Curriculum overall & $22(17.2 \%)$ & $13(4.8 \%)$ & $35(8.8 \%)$ \\
\hline Intent: Curriculum/Learning Areas & $29(22.7 \%)$ & $83(30.7 \%)$ & $112(28.1 \%)$ \\
\hline Operational guidance & $77(60.2 \%)$ & $174(64.4 \%)$ & $251(63.1 \%)$ \\
\hline Total & $128(100 \%)$ & $270(100 \%)$ & $398(100 \%)$ \\
\hline
\end{tabular}

\section{Knowledge: end or means?}

An interesting question lies in the stated purposes of the acquisition of knowledge. There were some differences between and within the two curricula in relation to mentions of knowledge as an end in its own right, compared to those framing it as an instrumental means to various purposes. This is illustrated in table 2 below.

Table 2: Knowledge as end, knowledge as means

\begin{tabular}{lrrrr}
\hline & \multicolumn{2}{c}{$\begin{array}{r}\text { The New Zealand } \\
\text { Curriculum }\end{array}$} & Curriculum for Excellence \\
\cline { 2 - 5 } & $\begin{array}{r}\text { Knowledge } \\
\text { as End }\end{array}$ & $\begin{array}{r}\text { Knowledge } \\
\text { as } \\
\text { Instrumental }\end{array}$ & $\begin{array}{r}\text { Knowledge } \\
\text { as End }\end{array}$ & $\begin{array}{r}\text { Knowledge } \\
\text { as } \\
\text { Instrumental }\end{array}$ \\
\hline Intent: Curriculum overall & $12(9.4 \%)$ & $10(7.8 \%)$ & $10(3.7 \%)$ & $3(1.1 \%)$ \\
\hline Intent: Curriculum/Learning Areas & $17(13.3 \%)$ & $12(9.4 \%)$ & $56(20.7 \%)$ & $27(10 \%)$ \\
\hline Operational guidance & $36(28.1 \%)$ & $41(32 \%)$ & $78(28.9 \%)$ & $96(35.6 \%)$ \\
\hline Total & $65(50.8 \%)$ & $63(49.2 \%)$ & $144(53.3 \%)$ & $126(46.7 \%)$
\end{tabular}

Note. Percentages indicate the percentage of within-country totals

In both the NZC and CFE there was a greater emphasis on the intrinsic value of knowledge than on the instrumental value of knowledge in sections dealing with overall curriculum and learning area intent. This greater emphasis was most marked in CFE, with more than three times the percentage of mentions of knowledge as end (as opposed to 
Priestley, M. and Sinnema, C. (2014). Downgraded curriculum? An analysis of knowledge in new curricula in Scotland and

New Zealand. Curriculum Journal, Special Edition: Creating Curricula: Aims, Knowledge, and Control

mentions of knowledge as instrumental) in the overall curriculum intent documentation. That pattern, in both NZC and CFE, was reversed in data from the operational guidance sections of the curricula. Here, statements of outcomes and achievement objectives tended to signal slightly greater emphasis on instrumental knowledge, as shown in the following examples:

\footnotetext{
Students will: Apply knowledge of the elements of music, structural devices, and technologies through integrating aural, practical, and theoretical skills. (NZC, The Arts, Music Level 4 achievement objective)

I can use my knowledge and skills of science and mathematics and can apply the basic principles of control technology in solving practical problems. (CFE,

Technologies Experiences and Outcomes, Level 4)
}

\section{Disciplinary or everyday knowledge?}

The first part of this paper has dealt primarily with high level messages about knowledge. A question raised by the social realists, but not yet addressed here, is whether these curricula blur the boundaries between disciplinary versus everyday knowledge. At this level of macro-level messages about knowledge, we make several observations. Many of the references to knowledge are generic, that they do not make explicit the difference between everyday and disciplinary knowledge, and this makes it difficult to differentiate analytically between these categories. Notwithstanding this failure to make explicit this distinction, it is clear that a large number of references (as illustrated by the extracts provided in the text to date) appear to be referring to disciplinary knowledge. The following two examples from the two curricula indicate the importance of disciplinary knowledge in the area of Science:

\footnotetext{
It involves generating and testing ideas, gathering evidence, including by making observations, carrying out investigations and modelling, and communicating and debating with others - in order to develop scientific knowledge, understanding, and explanations. (NZC, Science, p. 28)

Children and young people participating in the experiences and outcomes in the sciences will demonstrate a secure knowledge and understanding of the big ideas and concepts of the sciences (CFE, Building the Curriculum 3, Science, p 253)
} 
Priestley, M. and Sinnema, C. (2014). Downgraded curriculum? An analysis of knowledge in new curricula in Scotland and

New Zealand. Curriculum Journal, Special Edition: Creating Curricula: Aims, Knowledge, and Control

We can therefore conclude here that, at the level of statements of curricular intent at least, the intention is that disciplinary knowledge is accorded a high degree of importance, both in terms of intrinsic and instrumental value.

\section{Policy into practice; the status of knowledge in curricular guidance}

We might conclude from the above sections that both curricula, at least at the level of policy intention, place a strong emphasis on knowledge, as evidenced by the frequency with which it is mentioned. As we noted above, many references are generic in nature, failing to specify the nature of such knowledge, for example whether it has its origins in scientific disciplines or not. Nevertheless, one might argue that it is not the job of macro-level policy statements to define the content that is taught in schools - centralised input regulation (Nieveen \& Kuiper, 2012) - but instead to develop the conceptual frame within which either teachers might undertake school-based curriculum development. Put differently, the issue is whether 'to put the skills or intended capabilities in the foreground, as the framework, and leave subject-trained teachers to draw on their own expertise to work out how these were to be achieved $[\ldots$ or $]$ to leave subjects in place but to ask schools to work out ways to integrate these to develop the new capabilities' (Yates, Collins \& O’Connor, 2010, p. 316). There are thus legitimate questions about the ways in which CfE and the NZF guidance documentation specify content - in other words whether the policy guidance is more precise than the macrolevel statements of intent on the nature of knowledge to be acquired - and whether clear processes are specified to facilitate the development of programmes of content that reflect the importance placed upon knowledge in the high-level policy statements. The following sections of the paper address these issues, drawing empirically on the curricular documentation from both countries.

\section{Curricular design: the place of subjects}


Priestley, M. and Sinnema, C. (2014). Downgraded curriculum? An analysis of knowledge in new curricula in Scotland and

New Zealand. Curriculum Journal, Special Edition: Creating Curricula: Aims, Knowledge, and Control

In Scotland's Building the Curriculum 3 (Education Scotland, 2013), a key piece of guidance for schools, there is a specific section on curriculum areas and subjects. This strongly emphasises the essential nature of subjects as a way of structuring knowledge:

Subjects are an essential feature of the curriculum, particularly in secondary school.
They provide an important and familiar structure for knowledge, offering a context
for specialists to inspire, stretch and motivate. Throughout a young person's learning
there will be increasing specialisation and greater depth, which will lead to subjects
increasingly being the principal means of structuring learning and delivering
outcomes (p. 20)

Subject-based curriculum areas also remain a central feature of the NZC. Just as the CFE organises curriculum experiences and outcomes in curriculum areas (expressive arts, health and wellbeing, languages, mathematics, religious and moral education, science, social studies and technologies), the NZC outlines achievement objectives around eight learning areas (English, the arts, health and physical education, learning languages, mathematics and statistics, science, social sciences, and technology). The NZC describes learning associated with the eight areas as "part of a broad, general education [that] lays a foundation for later specialisation.

It is quite clear here that students' acquisition of new knowledge is viewed as desirable within both curricula. In both cases, domains of knowledge are specified as the foundation for developing curricular content. In both case, these domains are derived from previous policy. For example, in the Scottish case, one can trace this aspect of policy back to the seminal 1977 Munn report, reaffirming the 'Hirstian subject-based curriculum (Boyd, 1997, p.60). This lineage suggests that both curricula thus establish the framework for content that reflects disciplinary knowledge.

However, the situation is less clear cut than might seem at first glance. Given that matters of skill and competency and the like are also treated as desirable, what messages do the policies give about what matters most? Both curricula are articulated at the sharp end as 
outcomes, which tend to specify conceptual understandings or concepts or content only in the most general manner. For example:

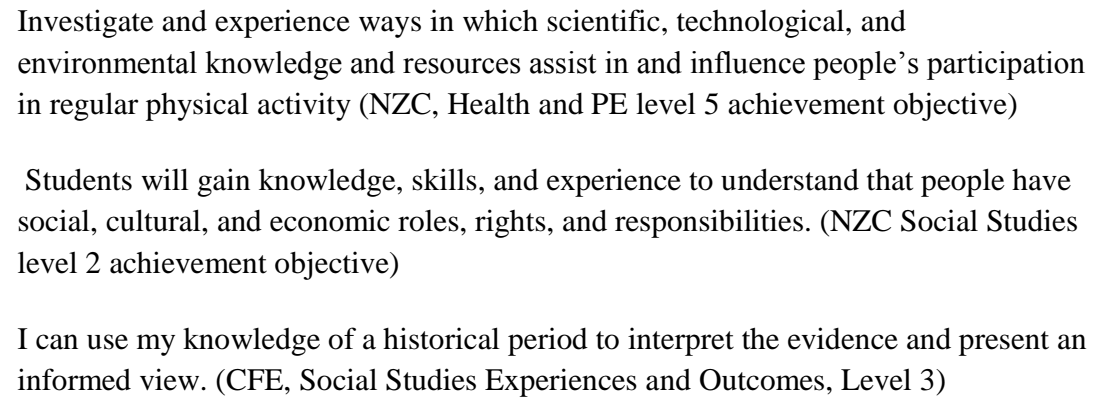

Minty and Priestley (2012), in their research on the implementation of CfE in one

Scottish local authority, noted the potential of the Es \& Os to be used by teachers to justify the continuation of existing practices, quoting a teacher who said:

\footnotetext{
I can cover all of these assessment parts in one, with one project here, one short project. It's not exactly the way they are saying it, but you are not saying we can't do it this way. And it meets all the criteria. I can tick all the boxes quite confidently. $[\ldots]$ that is one thing that you can see with Curriculum for Excellence: that the rules aren't quite as strict; you can tweak them without feeling too guilty. (p20)
}

Moreover, the focus on outcomes in both curricula neglects to specify processes for specifying knowledge. Our analysis showed clearly that there are no such processes, and we suggest that, along with the generic nature of the outcomes, there is a risk that the nature of knowledge acquired in school will be driven by more immediate concerns - assessment regimes, examinations syllabi, the availability of resources and routinised practices - rather than on consideration of what constitutes powerful knowledge.

\section{Design issues: inconsistencies and lack of coherence and alignment}

In our examination of curriculum documentation we noted the prevalence of mixed messages about the status of knowledge. This is especially evident in the extent to which the structure and text of the policies presented inconsistencies in emphasis and a lack of coherence in regard to the position of knowledge. The importance of knowledge is certainly 
Priestley, M. and Sinnema, C. (2014). Downgraded curriculum? An analysis of knowledge in new curricula in Scotland and

New Zealand. Curriculum Journal, Special Edition: Creating Curricula: Aims, Knowledge, and Control

present in statements of curricula intent, but not consistently so - there is a lack of alignment in positioning of knowledge within and across curriculum documents. Our analysis suggests that some texts strongly position knowledge (either exclusively or alongside other aspects, such as skills), whereas others emphasise only other aspects. There were discrepancies across different policy documents regarding the position and status of knowledge. Some curriculum intent statements focus exclusively on knowledge:

Learning through social studies extends children and young people's horizons and knowledge of time and place, and challenges them to look at the world in new ways. (CFE, Building the Curriculum 1, p. 34)

Others exclude specific mention of knowledge:

[CFE] should give young people the confidence, attributes and capabilities to make valuable contributions to society (Scottish Executive, 2004a, p. 11)

Even more (as outlined in Table 3 below) intent statements include reference to knowledge amongst a set of other desirable aspects.

Table 3: Knowledge as an exclusive end or part of a set

\begin{tabular}{lrrr}
\hline & $\begin{array}{c}\text { The New Zealand } \\
\text { Curriculum (NZC) }\end{array}$ & $\begin{array}{c}\text { Curriculum for } \\
\text { Excellence (CFE) }\end{array}$ & $\begin{array}{c}\text { Combined NZC and } \\
\text { CFE }\end{array}$ \\
\hline Exclusive & $44(67.7 \%)$ & $75(52.1 \%)$ & $119(56.9 \%)$ \\
\hline Part of a set & $21(32.3 \%)$ & $69(47.9 \%)$ & $90(43.1 \%)$ \\
\hline Total & $65(100 \%)$ & $144(100 \%)$ & $209(100 \%)$
\end{tabular}

Note: percentages indicate percentage of within-country totals

While these data illustrate that an exclusive focus on knowledge or knowledge and understanding is prevalent in both countries, a closer look at the sets of outcomes is revealing. What strikes us about those sets of outcomes were the inconsistencies within and across policy documents with regard to the aspects they include. As the selection below shows, typically knowledge is included alongside understanding and skills, but various other aspects are inconsistently included. Sometimes capabilities are included (see examples b, c, 
and h), sometimes they are not (see examples a, d, e, f, g and i). Sometimes attributes are included (see examples c, d, e and h), sometimes they are not (see examples a, b, f, g, and i), and similarly for understanding and abilities. There is a sense of the arbitrary in the construction of these statements about intention, which reduces the coherence of the curriculum for users.

a) more space in the curriculum for work in depth, and to ensure that young people develop the literacy, numeracy and other essential skills and knowledge they will need for life and work (Scottish Executive, 2004a, p. 4)

b) It is designed to convey knowledge which is considered to be important and to promote the development of values, understanding and capabilities (Scottish Executive, 2004a, p. 9)

c) Taken together, experiences and outcomes across the curriculum areas will sum up national aspirations for every young person: the knowledge and understanding, skills, capabilities and attributes we hope they will develop. (CFE, Building the Curriculum 1, p. 3)

d) Learning through health and wellbeing enables children and young people to: develop the knowledge and understanding, skills, abilities and attitudes necessary for their physical, emotional and social wellbeing now and in their future lives (CFE, Building the Curriculum 1, p. 6)

e) Approaches to learning and teaching should provide challenge and opportunities for children and young people to develop their knowledge and understanding, skills and attributes (CFE, Building the Curriculum 1, p. 10)

f) In Scotland, as in many countries in the world, active learning is seen as an appropriate way for children to develop vital skills and knowledge and a positive attitude to learning. (CFE, Building the Curriculum 2,p. 5)

g) Learning across all these experiences and outcomes will enable young people to develop breadth of knowledge and understanding and apply their skills in a wide range of contexts. (CFE, Building the Curriculum 3, p. 35)

h) The purposes of assessment are to: support learning that develops the knowledge and understanding, skills, attributes and capabilities which contribute to the four capacities (CFE, Building the Curriculum 5, p. 5)

i) Assessment will support learning and promote learner engagement resulting in greater breadth and depth in learning, including a greater focus on the secure development of knowledge, understanding and skills. (CFE, Building the Curriculum 5, p. 7) (emph. not in original)

These inconsistencies create a subtle, but pervasive sense of confusion about the purpose of curriculum - views about what actually matters and, even more importantly given the time 
Priestley, M. and Sinnema, C. (2014). Downgraded curriculum? An analysis of knowledge in new curricula in Scotland and

New Zealand. Curriculum Journal, Special Edition: Creating Curricula: Aims, Knowledge, and Control

constraints and complexities of schools and classroom, what matters most become unlikely to be shared amongst curriculum users.

Similar issues are evident in statements defining the New Zealand Curriculum national standards; for example, there are mixed messages about what they are, which arguably, leaves those charged with implementing the policies uncertain about whether they should focus on knowledge or not. In a document outlining questions and answers about the standards, their role in outlining what students should know (alongside what they should be able to do) is made explicit. In the reading and writing standards documents, however, the knowledge purpose is much less explicit, or even absent.

They [national standards] are descriptions of what students should know and be able to do in reading, writing, and mathematics at different points of their schooling from years 1-8. (New Zealand Ministry of Education, 2013, emph. not in original)

The standards will focus the education system on foundation skills and will link expectations about student progress and achievement to the demands of the New Zealand Curriculum (New Zealand Ministry of Education, 2009, p. 5, emph. not in original)

A similar misalignment is evident across two Scottish documents in statements about the experiences and outcomes of the CFE. In one, knowledge is the first in a list of aspirations that are described as being summed up by the experiences and outcomes. In the other, knowledge is absent in a description of what learning experiences should develop, whilst mention of capabilities and attributes remain.

\footnotetext{
These experiences and outcomes ... support the progressive development of ideas, skills and ways of thinking...Taken together, experiences and outcomes across the curriculum areas will sum up national aspirations for every young person: the knowledge and understanding, skills, capabilities and attributes we hope they will develop. (CFE, Building the Curriculum 1, p. 2-3)

The title 'experiences and outcomes' recognises the importance of the quality and nature of the learning experience in developing attributes and capabilities and in achieving active engagement, motivation and depth of learning. An outcome represents what is to be achieved. Taken as a whole, the experiences and outcomes embody the attributes and capabilities of the four capacities. (CFE, Experiences and Outcomes, p.3)
} 
Priestley, M. and Sinnema, C. (2014). Downgraded curriculum? An analysis of knowledge in new curricula in Scotland and

New Zealand. Curriculum Journal, Special Edition: Creating Curricula: Aims, Knowledge, and Control

Similar lack of alignment was apparent with regard to descriptions about the four capacities. In the outline of the four capacities, there is one mention of knowledge (REF CFE 2004) and that is in the text about the 'responsible citizens' capacity. It signals an aspiration for "citizens with respect for others, commitment to participate responsibly in political, economic, social and cultural life and able to develop knowledge and understanding of the world and Scotland's place in it" (p. 12). In the BTC1 document that outlines the contribution to the curriculum areas to the four capacities, we examined whether there was alignment; in other words, did the detail about the contribution of each of the learning areas to the capacity of 'responsible citizens' also refer to the importance of knowledge? We found that to be the case in only two of the nine areas - mathematics and social studies:

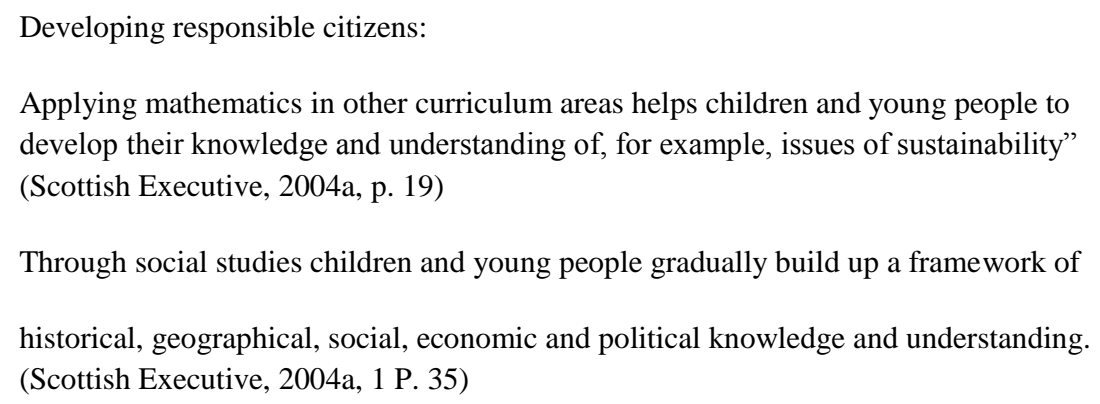

We suggest that these mixed messages reduce the certainty, or at least the clarity, of expectation that teachers emphasise knowledge.

\section{Discussion}

The answer to our question about whether knowledge has been downgraded is not as clear cut as perhaps claimed by some critics, as exemplified in the quotation that precedes the paper. It can be addressed at a number of levels: through analysis of high-level statements of intent; through clarity and coherence of guidance to practitioners; and ultimately, as curriculum should be seen as practice as well as policy, in its effects in schools as those practitioners make the curriculum through their daily interactions with students. 
Priestley, M. and Sinnema, C. (2014). Downgraded curriculum? An analysis of knowledge in new curricula in Scotland and

New Zealand. Curriculum Journal, Special Edition: Creating Curricula: Aims, Knowledge, and Control

At the highest level, we would argue knowledge continues to be a fundamental focus aims, purposes and goals within the new curriculum, at least in the context of NZC and CFE examined here. Disciplinary knowledge remains a purpose, and arguably one of the most the important purposes, of these curricula, and a key focus of the outcomes intended by curriculum policies.

Nonetheless, the acquisition of knowledge remains only one of a variety of purposes of education within the new curriculum, rather than the key purpose that distinguishes education from other activities, as advocated by social realists such as Young (2007). In such a context, one might therefore argue that in reducing the primacy of knowledge in the curriculum, governments are indeed downgrading knowledge. Moreover, we can add an observation here that, in both countries, there is an explicit intention that content should not be heavily prescribed, but should be flexible and subject to decision by local expects - the teachers who are best placed to make such decisions. The desired knowledge is therefore typically expressed as broad ideas or conceptual understandings which teachers should develop using content and through contexts of their own choice. Thus, this approach to curriculum policy specifies, for example, that students should "gain knowledge, skills and experiences to understand how cultural interaction impacts on cultures and societies." (NZC Social studies achievement objective, level 5). This contrasts with the national curriculum in England, which is far more prescriptive in its specification of the content to be learned:

Pupils should be taught about:

The achievements of the earliest civilizations - an overview of where and when the first civilizations appeared and a depth study of one of the following: Ancient Sumer, The Indus Valley, Ancient Egypt, The Shang Dynasty of Ancient China Ancient Greece - a study of Greek life and achievements and their influence on the western world [Department for Education, 2013, p. 208] 
Priestley, M. and Sinnema, C. (2014). Downgraded curriculum? An analysis of knowledge in new curricula in Scotland and

New Zealand. Curriculum Journal, Special Edition: Creating Curricula: Aims, Knowledge, and Control

These high level messages and the academic arguments about the relative importance of knowledge in the curriculum and the degree to which it should be specified are only part of the story. What seems equally important to us is our finding about mixed messages in the attention to and positioning of knowledge. Design issues (inconsistencies, lack of alignment, and lack of coherence) within and across policy texts are prevalent and lead to uncertainty for those receiving and implementing such policies. School leaders and teachers are potentially left, given the design issues, uncertain about what is most important and whether they should or should not prioritize attention to developing their students' knowledge.

In our view, calls to prescribe specific content at the level of national curricula (such as those made by various social realists) are not conducive to the increasing professionalisation of teaching. Rather, such specification contributes to issues such as those described by Swann, McIntyre, Pell, Hargreaves and Cunningham (2010) about teacher professionalism in England -a lack of trust in teachers by the public and by the government. The prominent but general indicators of the importance of knowledge in the NZC and CFE (without content specification) might be seen to signal a move away from the managerialist education policies widely critiqued in education, for their "emphasis on efficiency and external accountability [that] treats teachers as functionaries rather than professionals and thereby diminishes their autonomy and commitment" (Codd, 2005, p. 201). Rather, the professional space for teachers to determine content, assuming their recognition of the call to give students access to knowledge, might signal a shift towards higher levels of professional trust and a greater emphasis on teacher autonomy and agency as they make the curriculum in their local contexts $^{6}$. A further issue is the lack of specification in curriculum guidance in both countries of a process for deriving such knowledge from curricular purposes. What considerations

\footnotetext{
${ }^{6}$ For an extended discussion of whether teachers can indeed take advantage of the autonomy apparently afforded by the new curriculum, see Priestley, Biesta \& Robinson (2013)
} 
Priestley, M. and Sinnema, C. (2014). Downgraded curriculum? An analysis of knowledge in new curricula in Scotland and

New Zealand. Curriculum Journal, Special Edition: Creating Curricula: Aims, Knowledge, and Control

should teachers attend to in making decisions about content? How might they determine relative importance of content to develop knowledge in various circumstances? What processes should schools have for monitoring and reviewing the approach to content? These issues are not clearly explored in either curriculum. Thus, in terms of curricular practice, there remain at least two risks. One is that schools might downgrade knowledge. The other is the risk of content being specified for the wrong reasons: purely to meet the demands of assessment, to fit with existing resources, or simply to follow tradition, rather than through a process of thoughtful decisions about content that fits curricular purposes.

The influence of high stakes assessment on teaching and learning in schools, and the role it has in narrowing the curriculum, has been the source of much criticism (Berliner, 2011). Curriculum narrowing is harmful, he says, because it “reduces many students' chances of being thought talented in school and results in a restriction in the creative and enjoyable activities engaged in by teachers and students" (p. 287). Such criticism is unlikely to resonate with those arguing for greater emphasis on knowledge in curricula. It may, though, resonate with the call for powerful knowledge (Young and Muller, 2010), given findings such as those in a study Berliner cites, comparing Chinese and American university students (Bao et al., 2009). They were tested on their knowledge of force and their knowledge of electricity and magnetism. The Chinese students gained dramatically higher scores than their US counterparts. Their 'success' was explained by the narrowing of the curriculum (and narrowing of what constitutes knowledge in physics) due to the tyranny of high stakes assessment. Whether such findings indicate 'success' is questionable, since the other test involved in the study was one of scientific reasoning. On this measure, arguably the most important, Chinese students did no better than the American students. The high stakes 
Priestley, M. and Sinnema, C. (2014). Downgraded curriculum? An analysis of knowledge in new curricula in Scotland and New Zealand. Curriculum Journal, Special Edition: Creating Curricula: Aims, Knowledge, and Control

assessment and subsequent narrow curriculum seemed to have a detrimental impact in this regard.

The issue of curriculum narrowing is not confined to high stakes assessment. An empirical examination of the effect of low-stakes exit exams reveals that teachers teach to the test, even in assessments that do not involve external examiners or severe consequences (Jäger, Marki, Oerke \& Holmeier, 2012). Even low stakes assessment led teachers to ignore students' interests, bypass relevant current issues and narrow the curriculum.

In conclusion, we can state that both the NZC and CfE place a strong emphasis on the importance of acquiring knowledge, but they are less clear in specifying what knowledge is to be acquired or the processes which practitioners might follow in order to specify such knowledge. Moreover, analysis of the positioning of knowledge in relation to other curriculum elements in curriculum policy texts revealed mixed messages in respect of knowledge. Some features of the organisation, structure and emphasis of the texts support the claim that knowledge has been downgraded, whereas other features strongly point to a continued emphasis on knowledge, although not as the single most important curricular design aspect.

Thus, this empirical analysis partially supports the claim that these curricula have downgraded knowledge - they have greatly reduced the specification of content, deemphasised the importance of knowledge in relation to other aspects (skills, competencies etc.), and failed to provide explicit guidance on processes to the practitioners charged with developing them. Therefore, in spite of the strong emphasis given to knowledge in the highlevel statements of intent in both curricula, they run the risk that knowledge will be downgraded in practice, through inconsistent approaches to specifying content that is then potentially not fit for curricular purpose. 
Priestley, M. and Sinnema, C. (2014). Downgraded curriculum? An analysis of knowledge in new curricula in Scotland and New Zealand. Curriculum Journal, Special Edition: Creating Curricula: Aims, Knowledge, and Control

\section{Acknowledgement}

The authors would like to acknowledge Frauke Meyer from the University of Auckland for her invaluable assistance with this analysis of the NZCF and CfE

\section{References}

Australian Council of Educational Research. (2002). Report on the New Zealand National Curriculum. Retrieved from http://www.educationcounts.govt.nz/publications/curriculum/5823.

Bao, L., Cai, T., Koenig, L., Fang, K., Han, J., Wang, J., ... Wu, N. (2009). Physics: Learning and scientific reasoning. Science, 323, 586-587.

DOI: $10.1126 /$ science. 1167740

Biesta, G.J.J. (2011). Experience, Meaning and Knowledge: A Pragmatist View on Knowledge and the Curriculum. A paper presented at the ESRC seminar series, Curriculum for the 21st century: Theory, policy and practice (Seminar one: Knowledge and the Curriculum), Stirling, 21 February 2011.

Beane, J.A. (1997). Curriculum Integration: designing the core of a democratic education. New York: Teachers College Press

Berliner, D. (2011). Rational responses to high stakes testing: the case of curriculum narrowing and the harm that follows. Cambridge Journal of Education, 41, 287-302. DOI: 10.1080/0305764X.2011.607151.

Bernstein, B. (1990). The Structuring of Pedagogic Discourse: Class Codes and Control, Volume 4. London: Routledge.

Biesta, G.J.J. \& Priestley, M. (2013). A Curriculum for the Twenty-first Century? In M. Priestley \& G. J. J. Biesta (Eds.), Reinventing the curriculum: New trends in curriculum policy and practice (pp. 229-236). London: Bloomsbury. 
Priestley, M. and Sinnema, C. (2014). Downgraded curriculum? An analysis of knowledge in new curricula in Scotland and

New Zealand. Curriculum Journal, Special Edition: Creating Curricula: Aims, Knowledge, and Control

Boyd, B. (1997). The statutory years of secondary education: Change and progress. In M.M. Clark \& P. Munn (Eds.), Education in Scotland: policy and practice from pre-school to secondary (pp. 52-66). London, Routledge.

Brennan, M. \& Zipin, L. (2013). National Curriculum in a federation: shelving questions about democracy and equity in Australian schooling? Paper presented at the European Conference for Educational Research, Istanbul, 13 September, 2013.

Codd, J. (2005). Teachers as 'managed professionals' in the global education industry: The New Zealand experience, Educational Review, 57, 193-206.

DOI:10.1080/0013191042000308369

Department for Education. (2013). The National Curriculum in England: Framework document. Retrieved from https://www.gov.uk/government/uploads/system/uploads/attachment_data/file/210969 /NC_framework_document_-_FINAL.pdf .

Dewey, J. (1907). Waste in education. In J. Dewey (Ed.), The school and society: being three lectures by John Dewey supplemented by a statement of the University Elementary School. Retrieved from http://www.brocku.ca/MeadProject/Dewey/Dewey_1907/Dewey_1907c.html

Ecclestone, K. (2013). Confident individuals: the implications of an 'emotional subject' for curriculum priorities and practices. In M. Priestley \& G. J. J. Biesta (Eds.), Reinventing the curriculum: new trends in curriculum policy and practice (pp. 75-98). London: Bloomsbury.

Education Scotland. (2013). The curriculum in Scotland. Retrieved from http://www.educationscotland.gov.uk/thecurriculum/. 
Priestley, M. and Sinnema, C. (2014). Downgraded curriculum? An analysis of knowledge in new curricula in Scotland and

New Zealand. Curriculum Journal, Special Edition: Creating Curricula: Aims, Knowledge, and Control

Gardner, H. (1991). The unschooled mind: How children think and schools should teach. New York: Basic Books.

Gill, S. \& Thomson, G. (2012). Rethinking secondary education: A human-centred approach. Harlow: Pearson.

Goodson, I.F. \& Marsh, C.J. (1996). Studying school subjects: A guide. London: Falmer Press.

Jakobi, A.P. (2012). International organisations and policy diffusion: the global norm of lifelong learning. Journal of International Relations and Development, 15, 31-64. DOI: $10.1057 /$ jird.2010.20

Jäger, D. J., Marki, K. M., Oerke, B., \& Holmeier, M. (2012). Statewide low-stakes tests and a teaching to the test effect? An analysis of teacher survey data from two German states. Assessment in Education: Principles, Policy \& Practice, 19, 451-467. DOI: 10.1080/0969594X.2012.677803

Kelly, A. V. (1999). The curriculum: Theory and practice, 4th edition. London: Sage.

Le Métais, J. (2002). New Zealand stocktake: An international critique. Wellington: The Ministry of Education. Retrieved from http://www.educationcounts.govt.nz/_data/assets/pdf_file/0019/9451/nz-stocktakean-international-critique.pdf.

Minty, S. \& Priestley, M. (2012). Developing Curriculum for Excellence: Summary of research findings from a Scottish local authority. Stirling: University of Stirling.

Moore, R. \& Young, M. (2001). Knowledge and the curriculum in the sociology of education: towards a reconceptualization. British Journal of Sociology of Education, 22, 445-461. DOI:10.1080/01425690120094421 
Priestley, M. and Sinnema, C. (2014). Downgraded curriculum? An analysis of knowledge in new curricula in Scotland and

New Zealand. Curriculum Journal, Special Edition: Creating Curricula: Aims, Knowledge, and Control

New Zealand Herald. (2013). Knowledge lost from our kids' learning: expert. 7 September, 2013. Retrieved from http://www.nzherald.co.nz/nz/news/article.cfm?c id=1\&objectid=11120936.

New Zealand Ministry of Education. (2007). The New Zealand Curriculum. Wellington: Learning Media.

New Zealand Ministry of Education. (2009). Reading and Writing Standards for years 1-8. Retrieved from http://nzcurriculum.tki.org.nz/National-Standards/Reading-andwriting-standards.

New Zealand Ministry of Education. (2013). National Standards Questions and Answers. Retrieved from http://nzcurriculum.tki.org.nz/National-Standards/Keyinformation/Questions-and-answers

Nieveen, N. \& Kuiper, W. (2012). Balancing curriculum and freedom in the Netherlands. European Educational Research Journal, 11, 357-368. DOI: 10.2304/eerj.2012.11.3.357

Phillips, D., \& Ochs, K. (2003). Processes of Policy Borrowing in Education: some explanatory and analytical devices. Comparative Education, 39, 451-461. DOI: $10.1080 / 0305006032000162020$

Pickering, M.J. (2004). Qualitative Content Analysis. In M.S. Lewis-Beck, A. Bryman \& T. F. Liao (Eds.), Encyclopedia of Social Science Research Methods (pp. 890-891) Thousand Oaks, Calif: Sage.

Priestley, M. (2011). Whatever happened to curriculum theory? Critical realism and curriculum change. Pedagogy, Culture and Society, 19, 221-237. DOI:10.1080/14681366.2011.582258 
Priestley, M. and Sinnema, C. (2014). Downgraded curriculum? An analysis of knowledge in new curricula in Scotland and

New Zealand. Curriculum Journal, Special Edition: Creating Curricula: Aims, Knowledge, and Control

Priestley, M., Biesta, G.J.J. \& Robinson, S. (2013). Teachers as agents of change: Teacher agency and emerging models of curriculum. In M. Priestley \& G.J.J. Biesta (Eds.), Reinventing the curriculum: New trends in curriculum policy and practice (pp. 187206). London: Bloomsbury.

Priestley, M., Robinson, S. and Biesta, G. J. J. (2012). Teacher Agency, Performativity and Curriculum Change: Reinventing the Teacher in the Scottish Curriculum for Excellence? In B. Jeffrey \& G. Troman (Eds.), Performativity across UK education: Ethnographic cases of its effects, agency and reconstructions (pp. 87-108). Painswick: EandE Publishing.

Rapley, T. \& Jenkings, K.N. (2010). Document Analysis. In P. Peterson, E. Baker \& B. McGaw (Eds.), The International Encyclopedia of Education, Third Edition (pp. 380385). Oxford: Elsevier

Rata, E. (2012a). The politics of knowledge in education. British Educational Research Journal, 38, 103-124. DOI:10.1080/01411926.2011.615388

Rata, E. (2012b). The Politics of Knowledge in Education. London: Routledge.

Scottish Executive. (2004a). A Curriculum for Excellence: The Curriculum Review Group. Edinburgh: Scottish Executive.

Scottish Executive. (2004b). A Curriculum for Excellence: Ministerial Response. Edinburgh: Scottish Executive.

Scottish Executive. (2006). A Curriculum for Excellence: progress and proposals. Edinburgh: Scottish Executive.

Sinnema, C. (2011). Monitoring and evaluating curriculum implementation: Final evaluation report on the implementation of the New Zealand Curriculum, 2008-2010. Wellington: New Zealand Ministry of Education. 
Priestley, M. and Sinnema, C. (2014). Downgraded curriculum? An analysis of knowledge in new curricula in Scotland and

New Zealand. Curriculum Journal, Special Edition: Creating Curricula: Aims, Knowledge, and Control

Sinnema, C. \& Aitken, G. (2013). Trends in International Curriculum Development. In M. Priestley \& G. J. J. Biesta (Eds), Reinventing the curriculum: New trends in curriculum policy and practice (pp. 141-164). London: Bloomsbury.

Swann, M., McIntyre, D., Pell, T., Hargreaves, L., \& Cunningham, M. (2010). Teachers' conceptions of teacher professionalism in England in 2003 and 2006. British Educational Research Journal, 36, 549-571. DOI: 10.1080/01411920903018083

Watson, C. (2010). Educational policy in Scotland: inclusion and the control society. Discourse: Studies in the Cultural Politics of Education, 31, 93-104.

DOI:10.1080/01596300903465443

Weber, R. P. (1990). Basic Content Analysis, $2^{\text {nd }}$ Edition. Newbury Park, CA: Sage.

Wheelahan, L. (2010). Why knowledge matters in curriculum: A social realist argument. London: Routledge.

White, J. (2011). Exploring well-being in schools: A guide to making children's lives more fulfilling. London: Routledge.

Whitty, G. (2010). Revisiting school knowledge: Some sociological perspectives on new school curricula. European Journal of Education, 45, 28-44. DOI: 10.1111/j.14653435.2009.01422.x

Yates, L. \& Collins, C. (2010). The absence of knowledge in Australian curriculum reforms. European Journal of Education, 45, 89-101. DOI: 10.1111/j.1465-3435.2009.01417.x

Yates, L., Collins, C. \& O'Connor, K. (2010). Curriculum in Australia: the challenges, the past and the future. In L. Yates, C. Collins and K. O'Connor (Eds.), Australia's curriculum dilemmas : State cultures and the big issues (pp. 309-326) Carlton, Vic. : Melbourne University Publishing. 
Priestley, M. and Sinnema, C. (2014). Downgraded curriculum? An analysis of knowledge in new curricula in Scotland and New Zealand. Curriculum Journal, Special Edition: Creating Curricula: Aims, Knowledge, and Control

Yates, L. \& Young, M. (2010). Editorial: globalization, knowledge and the curriculum. European Journal of Education, 45, 4-10. DOI: 10.1111/j.1465-3435.2009.01412.x

Young, M. (2007). Bringing Knowledge Back In: From social constructivism to social realism in the sociology of education. London: Routledge.

Young, M. (2008). From Constructivism to Realism in the Sociology of the Curriculum. Review of Research in Education, 32, 1-28. DOI :10.3102/0091732X07308969

Young, M. (2009). Alternative Educational Futures for a Knowledge Society. Socialism and Education. Retrieved from http://socialismandeducation.wordpress.com/2009/12/06/alternative-educationalfutures-for-a-knowledge-society (accessed on 29/01/10).

Young, M. and Muller, J. (2010). Three Educational Scenarios for the Future: lessons from the sociology of knowledge. European Journal of Education, 45(1), 11-27.

\section{Appendix A}

Knowledge Coding Framework 


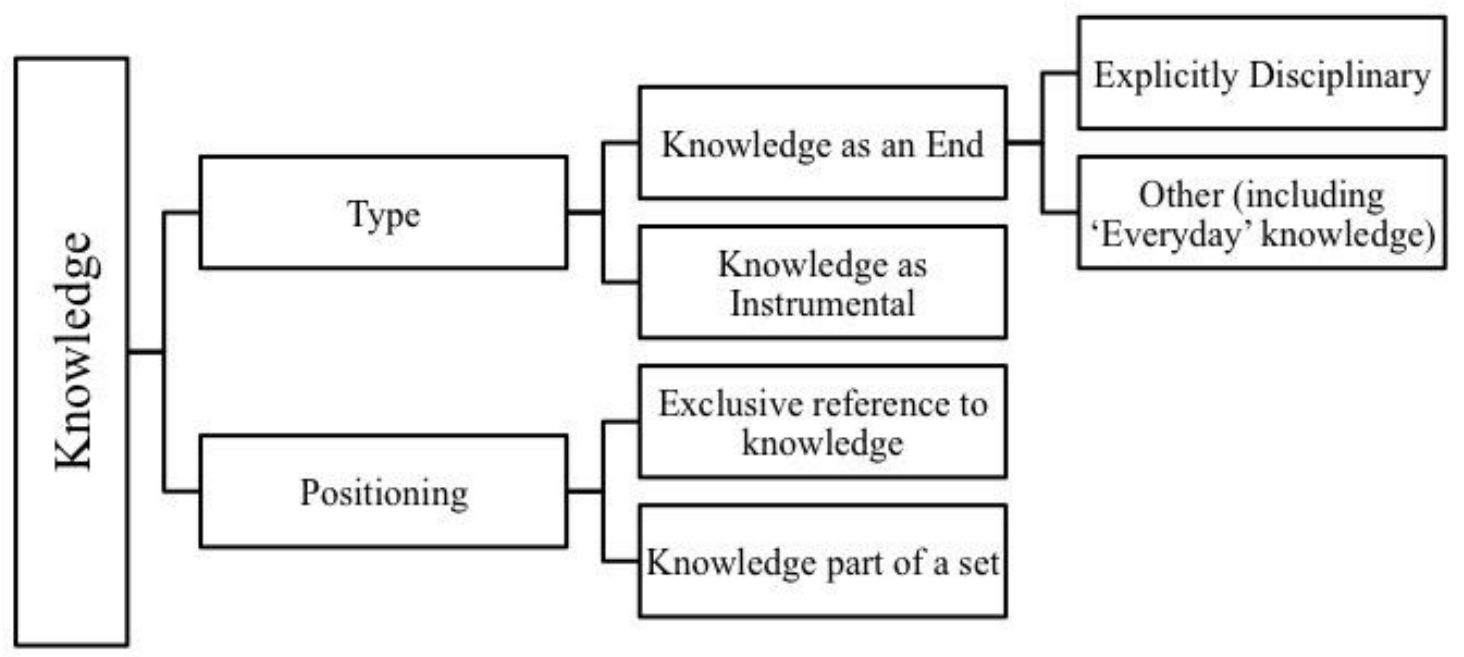

